\section{Microbial contamination of pumice used in dental laboratories}

\author{
Farzaneh Firoozeh, ${ }^{1}$ Mohammad Zibaei, \\ Abolfazl Zendedel, ${ }^{3}$ \\ Hushang Rashidipour, ${ }^{4}$ Aziz Kamran ${ }^{5}$ \\ 'Department of Microbiology and \\ Immunology, School of Medicine, Kashan \\ University of Medical Sciences, Kashan; \\ 2Department of Parasitology and \\ Mycology, School of Medicine, Lorestan \\ University of Medical Sciences, Khorram \\ Abad; ${ }^{3}$ Department of Internal Medicine, \\ School of Medicine, Lorestan University \\ of Medical Sciences, Khorram Abad; \\ ${ }^{4}$ Department of Endodontics, Dental \\ School, Lorestan University of Medical \\ Sciences, Khorram Abad; ${ }^{5}$ Department \\ of Public Health, Isfahan University of \\ Medical Sciences, Isfahan, I.R. Iran
}

\section{Abstract}

Dental appliances as well as sending and receiving prosthesis from laboratories are potential sources of cross-contamination for technicians, dentists, patients and can transmit different infectious agents as well. This study was conducted to determine the types of the microorganisms in pumice powder and pumice slurry used in dental laboratory in order to evaluate necessary disinfection control procedure in the dental settings. Twenty-four active dental laboratories of Khorram Abad participated in our study. Samples were randomly collected from prosthesis polishing containers in sterilized condition and were immediately sent to microbiology laboratory. Specimens were cultured on selective bacterial and fungal media in order to determine the microorganisms. Both oral and non-oral bacteria were recovered from pumice samples as follows: Staphylococcus aureus (15.4\%), Streptococcus viridance (10.8\%), Bacillus cereus (18.7\%), Pseudomonas aeruginosa (12.8\%), Diphtheriods (7.3\%), Enterobacter cloace (4.3\%), Escherichia coli (13.1\%), Klebsiella pneumonia (5.4\%), and Acinetobacter spp. (12.2\%). The isolated fungi included Candida albicans (36.7\%), other yeasts (17.3\%), Fusarium spp. (13.8\%), Aspergilus spp. (22.4\%) and Penicillium spp. (9.8\%). This study showed that polishing pumices in the form of powder or slurry were contaminated with different oral and non-oral bacteria and also fungi. Therefore, the chance of cross-contamination still severely exists, and measures should be conducted to prevent the contamination of predisposed people such as technicians, dentists and patients.

\section{Introduction}

Cross-contamination is a serious problem in dentistry and may occur among dental staff and patients. ${ }^{1}$ Dental patients and dental personnel (dentists, dental laboratory technicians and assistants) can be exposed to a wide variety of pathogenic microorganisms in the blood and saliva, such as hepatitis B virus (HBV), hepatits C virus (HCV), HIV, pseudomonas, Acinetobacter, Diphteroids, Lactobacilli, Staphylococci, Streptococci, Mycobacterium and other microorganisms that colonize the oral cavity and respiratory tract. These organisms can be transmitted to dental settings through direct or indirect contact. . $^{2,3}$

Most recent literature has focused on crosscontamination of dental prostheses in the dental laboratory. ${ }^{4,5}$ In dental laboratories, pumice is used in prostheses polishing. The pumice as the last step of prosthesis finishing - has been reported to be the greatest source of contamination and also a transmission potential source for infection. ${ }^{6,7}$ During prosthesis polishing, contaminated aerosol particles spread and remain in the air for a long time causing high risks for both dental staff and patients. Aspiration and inhalation of these aerosols for elderly immunocompromised patients, patients with endocarditis and respiratory disease is really hazardous. ${ }^{8,9}$

The bacteria, such as Acinetobacter, Pseudomonas and Moraxella, which are not part of normal oral flora, can cause serious diseases if passed to patients whose dentures are polished with contaminated material and to the technician by exposure to contaminated aerosol. ${ }^{10}$

The prosthesis contaminated by potentially pathogenic microorganisms such as Gram negative bacilli can cause serious diseases when it penetrates the oropharyngeal area and increases pneumonia incidence. ${ }^{7}$ Despite rigorous need for sterilization and disinfection of dental instruments, prosthetic appliances do not receive adequate infection control. ${ }^{11}$ The sterilization has to be performed with suitable validated procedures so that the success of these procedures can be monitored and safety and health of patients, users, and other persons guaranteed. ${ }^{12}$ An earlier research from Shiraz area (Iran) reported the microorganisms isolated from pumice in dental laboratories. ${ }^{7}$ The aim of this research was to determine the bacterial and fungal contaminations present in pumice powder and slurry used in Khorram Abad dental laboratories to evaluate the role of pumice in cross-contamination of dental laboratories.
Correspondence: Mohammad Zibaei, Department of Parasitology and Mycology, School of Medicine, Lorestan University of Medical Sciences, Khorram Abad, Iran.

Tel. +98.661.6200133 - Fax: +98.661.6200149.

E-mail: zibaeim@sums.ac.ir

Key words: contamination, microbial, pumice, dental laboratory.

Contributions: FF, conception and design of the study, critical revision of the article for important intellectual content; MZ, administrative, technical or logistical support, final approval of the study, guarantor of integrity of the entire study; $\mathrm{AZ}$, obtaining funding for the study; HR, provision of study material or patients, collection; AK, analysis and interpretation of data.

Funding: the work was supported by the Vice Chancellor for research of Lorestan University of Medical Sciences, Khorram Abad, Iran.

Conflict of interests: the authors declare no potential conflict of interests.

Received for publication: 11 December 2012. Revision received: 13 February 2013.

Accepted for publication: 16 February 2013.

This work is licensed under a Creative Commons Attribution 3.0 License (by-nc 3.0).

(c) Copyright F. Firoozeh et al., 2013

Licensee PAGEPress, Italy

Healthcare in Low-resource Settings 2013; 1:e5 doi:10.4081/hls.2013.e5

\section{Materials and Methods}

\section{Survey area}

Khorram Abad, the capital of Lorestan province is located in the south-west Iran, bordering with the provinces of Markazi, Hamedan, Kermanshah, Khuzestan, Ilam, and Isfahan. The estimated population of Khorram Abad is 540,000. The district covers an area of approximately $6233 \mathrm{~km}^{2}$. The study site $\left(48^{\circ} 21^{\prime} \mathrm{S}, 30^{\circ} 43^{\prime} \mathrm{W}\right)$ is the largest city in Lorestan province.

\section{Sample collection}

This study was conducted between June and September 2012 in twenty-four dental laboratories in Khorram Abad. Samples randomly collected were placed in sterile containers and immediately transferred to the microbiology laboratory for isolation of microorganisms.

Preparation, cultivation and identification

Initially, $1 \mathrm{~g}$ of pumice was aseptically weighed and a suspension in $9 \mathrm{~mL}$ sterile normal saline was prepared in a small test tube. 
the tubes were mixed for $30 \mathrm{sec}$. afterwards, 1 $\mathrm{ml}$ of the suspension was cultured on blood agar [automatic tank dewater (ATD); Antec International Ltd., Sudbury, UK] with 5\% defibrinated sheep blood cell for isolation of all bacteria, on McConkey agar (MERCK KGaA, Darmstadt, Germany) for isolation of Gram negative bacteria, on manitol salt agar (MERCK KGaA) for isolation of Staphylococcus aureus, and on Sabouroud dextrose agar (HiMedia Laboratories Ltd., Mumbai, India) for detection of fungi. The cultured plates were incubated $24-48 \mathrm{~h}$ at $37^{\circ} \mathrm{C}$ for bacterial isolation and at $25^{\circ} \mathrm{C}$ for 2 weeks for fungi. The plates were checked daily for detection of microorganisms. Morphologically different bacterial and fungal colonies were subcultured, and isolated colonies were identified to genus and species levels using microscopic and macroscopic characters. ${ }^{7}$ In addition, coagulase, catalase, sugar fermentation test, $\mathrm{KOH}$ and hemolysis test were carried out according to the standard methods. ${ }^{13}$ To assure the sterility and reliability of the techniques, 24 nontreated pumices (with denture) for each dental laboratory were considered as the control group.

\section{Results}

Of the 72 samples collected from 24 dental laboratories, 16 (66.7\%) dental laboratories were contaminated for microorganisms (Table 1). The isolated microorganisms from cultures of pumice samples collected from dental laboratories in Khorram Abad are reported in Figures 1 (Gram positive bacteria) and 2 (Gram negative bacteria). The results indicated that the highest rate belonged to Bacillus cereus (18.7\%) and the lowest one was Enterobacter cloace (4.3\%). Candida albicans (36.7\%) was the highest rate of isolated fungi and Penicillium spp. (9.8\%) was the lowest (Figure 3).

\section{Discussion}

Pumice used as the last step in prosthesis polishing could be a potential source of contamination to dental laboratory technicians. ${ }^{10}$ It was shown that in patients with immune deficiency problems, dentures have higher levels of contamination, ${ }^{14,15}$ since most denture users are elderly people, so the risk of infection is even higher. In this study, we found a great part of bacterial species from pumices. Most interestingly, this is consistent with report by Verran et al., ${ }^{16}$ although they also isolated Micrococcus from pumice slurry.

Results obtained in the present study revealed a strong oral and non-oral contaminating source in polishing pumices. Most of the fungi and bacteria isolated in our study were not pathogenic in healthy people, but some of them, such as Staphylococcus aureus and Streptococcus viridans, can be harmful both for the immunoicompromised and elderly patients as well as for healthy people.

Viridans streptococci are part of the oral cavity normal flora. The main significance of these bacteria relates to their ability to cause $30-40 \%$ of cases of subacute bacterial endocarditis. ${ }^{14}$ Since the organisms are most abundant in the mouth, minor trauma may lead to their entry into the bloodstream and initiate of endocarditis especially in predisposed patients. Witt et al. ${ }^{8}$ notified a similar situation. They found Streptococcus viridians in cultures of pumice from laboratories.

When prosthesis is polished with pumice,

Table 1. Microorganisms isolated from dental laboratories.

\begin{tabular}{|c|c|c|c|c|c|c|c|c|c|c|c|c|c|c|}
\hline \multirow[t]{2}{*}{ No. } & \multirow[b]{2}{*}{ S.vi. } & \multirow[b]{2}{*}{ S.ae } & \multirow[b]{2}{*}{ B.ce. } & \multirow[b]{2}{*}{ Pae } & \multirow[b]{2}{*}{ Dipht. } & \multirow[b]{2}{*}{ E.co. } & \multicolumn{3}{|c|}{ Lab.Microorganisms } & \multirow[b]{2}{*}{ C.al. } & \multirow[b]{2}{*}{ Other } & \multirow[b]{2}{*}{ Fusa. } & \multirow[b]{2}{*}{ Aspe. } & \multirow[b]{2}{*}{ Peni. } \\
\hline & & & & & & & E.cl. & K.pn. & Acin. & & & & & \\
\hline 1 & + & + & - & - & - & - & - & + & - & + & - & - & - & - \\
\hline 2 & - & + & - & + & + & - & - & - & + & + & + & - & + & + \\
\hline 3 & - & - & - & + & + & - & + & - & + & + & + & - & + & - \\
\hline 4 & - & - & + & + & - & - & + & - & + & + & - & + & + & - \\
\hline 5 & - & - & + & + & - & - & + & - & + & + & + & + & - & - \\
\hline 6 & - & + & - & + & + & + & + & - & + & + & + & + & + & - \\
\hline 7 & - & + & - & + & + & + & - & - & + & - & - & + & + & + \\
\hline 8 & + & + & - & + & - & - & - & + & + & - & - & + & + & + \\
\hline 9 & - & - & + & - & + & + & - & - & - & + & - & - & - & + \\
\hline 10 & - & - & + & - & - & - & - & - & - & + & + & - & + & - \\
\hline 11 & - & - & + & - & - & + & - & - & - & - & + & - & + & - \\
\hline 12 & - & - & + & - & - & + & - & - & - & + & + & - & + & - \\
\hline 13 & - & + & - & - & - & - & - & + & - & + & - & - & + & + \\
\hline 14 & - & - & - & - & - & - & - & + & - & + & - & - & + & - \\
\hline 15 & - & - & - & - & + & + & - & + & - & + & + & + & - & - \\
\hline 16 & - & + & - & + & - & + & - & - & - & - & - & + & - & - \\
\hline 17 & - & - & - & + & + & + & - & - & - & - & - & + & - & - \\
\hline 18 & - & - & - & - & - & + & + & - & - & - & - & + & - & + \\
\hline 19 & - & - & - & - & + & + & + & - & - & - & - & - & + & - \\
\hline 20 & - & - & + & + & + & - & + & - & - & - & - & - & - & - \\
\hline 21 & + & + & - & + & - & - & + & - & - & - & - & - & - & - \\
\hline 22 & - & + & - & - & - & - & + & - & + & + & - & - & - & + \\
\hline 23 & - & + & - & + & - & - & - & - & + & - & - & - & - & + \\
\hline 24 & - & - & - & + & + & - & - & - & + & + & + & - & - & + \\
\hline
\end{tabular}

S.vi., Streptococcus viridance; S.ae., Staphylococcus aureus; B.ce., Bacillus cereus; Pae., Pseudomonas aeruginosa; Dipht., Diphtheriods; E.co., Escherichia coli; E.cl., Enterobacter cloace; K.pn., Klebsiella pneumonia; Acin., Acinetobacter species; C.al., Candida albicans; Other, other yeasts; Fusa., Fusarium species; Aspe., Aspergilus species; Peni., Penicillium species. 
contaminated aerosol particles of microorganisms such as Gram negative bacteria and fungi, are spread all around the laboratory. This could be a major source for different oral and non-oral infections. Several studies have reported isolation of Gram negative bacteria like Pseudomonas, Moraxella and Acinetobacter from pumice which can be transferred to patients and dental laboratory staff by

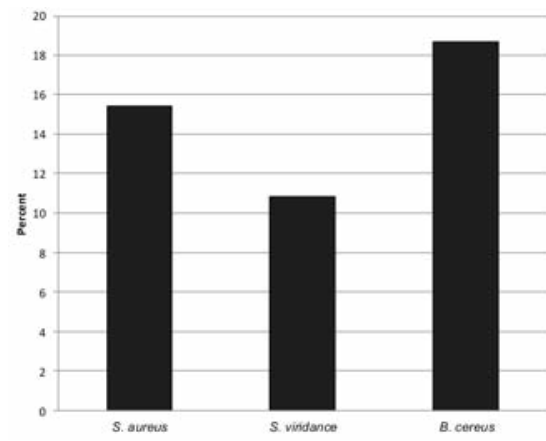

Figure 1. Frequency of Gram positive bacteria isolated from pumice samples of dental laboratories.

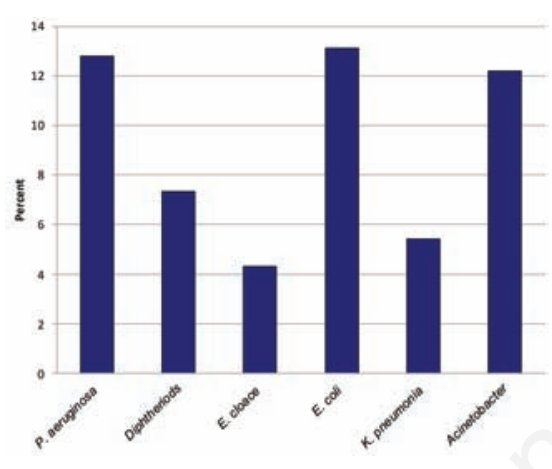

Figure 2. Frequency of Gram negative bacteria isolated from pumice samples of dental laboratories.

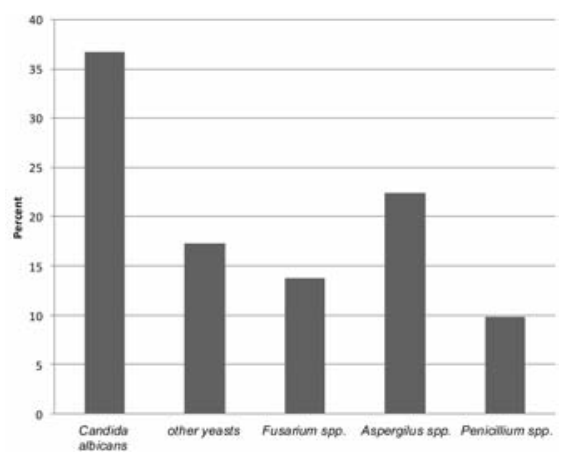

Figure 3. Fungal species isolated from pumice samples. contaminated aerosols, and cause ocular and respiratory infection especially in persons with chronic respiratory disorders. ${ }^{16}$ The entry of Gram negative bacteria such as Escherichia coli, Enterobacter and Klebsiella into the blood of patients can cause a fatal infection especially Gram negative septicemia in debilitated patients. ${ }^{17}$ Isolation of Gram negative bacteria in the current study is similar to that obtained by other studies. ${ }^{7}$

Fungi recovered from used pumice samples in the current study included Aspergillus, Fusarium, Penicillium and Candida that increased risk of fungal infection especially in persons who work for a long period of time in dental laboratories and have been exposed to fungal spores. ${ }^{18}$ Some reports support that Candida albicans belong to the normal physiology flora of mouth. It is able to grow in pumice and cause infections in humans. ${ }^{19}$

Besides, new studies have been conducted on viral infection transmission especially $\mathrm{HBV}$ and HIV in dental laboratories. Occupational infection of the dental laboratory technicians with HBV has been reported. The studies suggest that all healthcare workers working in dental laboratories should be vaccinated against hepatitis $\mathrm{B}$ virus. ${ }^{20}$

There are many studies that provide some additional information regarding prosthesis disinfection. A previous study in Brazil showed a transfer of microorganisms from patients prosthesis to sterile prosthesis and in most laboratories pumice was not changed or disinfected between polishing procedures. ${ }^{10}$ Jagger et al. ${ }^{21}$ reported that about $6.1 \%$ of dental laboratories used disinfectants in the pumice and $92.9 \%$ did not disinfect the polishing instrument. A previous study has proven that pumice slurry freshly made up using disinfectants was reported to be free from most contaminations. ${ }^{8}$ Unfortunately, in the present study most of the laboratories did not used a disinfectant while working with pumice, however, it will be good to use such disinfection protocol to minimize the chance of infection among the dental laboratories technicians and patients. It is recommended to disinfect old or used dentures before starting any action. The technician should use sterilized gloves, disinfected protecting glasses, oral masks, brushes and polishing tools to polish prosthesis.

\section{Conclusions}

Polishing pumices are potential source of infection in dental laboratories when considering the wide variety of microorganisms in the blood and saliva of patients. Following our study results, low temperature sterilization, such as gas or plasma sterilization, would allow optimal reduction in the number of path- ogenic bacteria. The use of sterile pumice or association of disinfectants with pumice for polishing the prosthesis, sterilization of containers after each use with adding of an appropriate disinfectant such as $0.2 \%$ chlorohexidine gluconate or $5 \%$ hypochlorite sodium to pumice could be effective and daily change of polishing paste is recommended to reduce the hazard of cross-contamination. However, no standard procedures actually exist.

\section{References}

1. Kugel G, Perry RD, Ferrari M, Lalicata P. Disinfection and communication practices: a survey of U.S. dental laboratories. J Am Dent Assoc 2000;131:786-92.

2. Al-Saadi AK. Bacterial cross-contamination between clinic \& dental laboratory during polishing procedure of complete denture. Mustansiria Dental Journal 2011;8:288-92. Available from: http://www. iasj.net/iasj?func=issueTOC\&isId $=1872 \&$ uiLanguage $=$ en

3. Al-Kheraif AA, Mobarak FA. Infection control practice in private dental laboratories in Riyadh. Saudi Dent J 2008;20:163-9.

4. Debattista N, Zarb M, Portelli JM. Bacterial cross-contamination between the dental clinic and laboratory during prosthetic treatment. Malta Med J 2010;22:17-9.

5. Parisi E, Glick M. Immune suppression and considerations for dental care. Dent Clin N Am 2003;47:709-31.

6. King AH, Matis B. Infection control of inoffice dental laboratories. Dent Clin N Am 1991;35:415-26.

7. Vojdani M, Zibaei M. Frequency of bacteria and fungi isolated from pumice in dental laboratories. J Res Health Sci 2006;6:33-8.

8. Witt S, Hart P. Cross infection hazards associated with the use of pumice in dental laboratories. J Dent 1990;18:281-3.

9. Chris H, Miller C, John P. Infection control and management of hazardous materials for the dental team. 2nd ed. London: Mosby; 1998.

10. Agostinho AM, Miyoshi PR, Gnoatto N, et al. Cross-contamination in dental laboratory through the polishing procedure of complete dentures. Braz Dent J 2004;15: $138-43$.

11. Williams DW, Chamary N, Lewis MA, et al. Microbial contamination of removable prosthodontic appliance from laboratories and impact of clinical storage. Brit Dent $\mathrm{J}$ 2011;26:163-6.

12. Smith PN, Palenik CJ, Blanchard SB. Microbial contamination and the sterilization/disinfection of surgical guides used in the placement of endosteal implants. Int J Oral Max Impl 2011;26:274-81. 
13. Washigton W Jr, Allen S, Janda W, et al. Color atlas and Textbook of Diagnostic Microbiology. Philadelphia, PA: Lippincott Williams \& Wilkins; 2006.

14. Henderson CW, Schwartz RS, Herbold ET, Mayhew RB. Evaluation of the barrier system, an infection control system for the dental laboratory. J Prosthet Dent 1987;58:517-21.

15. Verran J, Winder C, McCord JF, Maryan CJ. Pumice slurry as a cross infection hazard in nonclinical (teaching) dental technolo- gy laboratories. Int J Prosthodont 1997;10:283-6.

16. Williams HN, Falkler WA Jr, Hasler JF. Acinetobacter contamination of laboratory dental pumice. J Dent Res 1983;62:1073-5.

17. Schuoter GS. Microbiology of the orofacial region in Topazian, oral and maxillofacial infection. 4th ed. Philadelphia, PA: WB Saunders; 2002.

18. Williams HN, Falkler WA Jr, Smith AG, Hasler JF. The isolation of fungi from laboratory dental pumice. J Prosthet Dent
1986;56:77-80

19. de Resende MA, Souza LVNF, Oliveira RCBW, et al. Prevalence and antifungal susceptibility of yeasts obtained from the oral cavity of elderly individuals. Mycopathologia 2006;162:39-44.

20. Al-Dwarai ZN. Infection control procedures in commercial dental laboratories in Jordan. J Dent Educ 2007;71:1223-7.

21. Jagger DC, Huggett R, Harrison A. Crossinfection control in dental laboratories. Brit Dent J 1995;179:93-6. 